\title{
The Child with Recurrent Infections
}

\author{
Arnoldo Quezada, M.D* \\ Department of Pediatrics, School of Medicine, University of Chile, Santiago, Chile
}

*Corresponding Author: Arnoldo Quezada, Department of Pediatrics, School of Medicine, University of Chile, Santiago, Chile, Email: aquezada@med.uchile.cl

\begin{abstract}
The child with recurrent infections proposes a diagnostic challenge to discard an immunodeficiency. There is no definitive consensus to determine the number of infections that can be considered normal. Children with recurrent infections can be included in four basic types of diagnostic categories: probably normal child, allergic child, children with chronic disease, and immunodeficient child. Different warning signs have been developed to guide the appropriate detection of children with primary immunodeficiency diseases (PID). The value of a detailed clinical history and an exhaustive physical examination, as well as the study with initial laboratory tests are discussed. Some PID may be suspected as more probable depending on the infectious agent.
\end{abstract}

Keywords: primary immunodeficiency, recurrent infections, warning signs.

Recurrent infections in children may be the most prominent symptom to suspect an immunodeficiency, but they can also occur in children without alterations in their immunological competence. An unresolved problem is still to determine the number of infections that can be considered normal at a certain age. Six to ten upper respiratory infections per year, usually viral, are accepted as normal in infants if they evolve without complications. When these "normal" infections are interspersed with one or two bacterial infections they may correspond to an immunodeficiency or some other serious problem. According to some authors, two systemic bacterial infections (such as sepsis, meningitis or osteomyelitis) or three respiratory infections (pneumonia, sinusitis, etc.) or bacterial infections (cellulitis, lymphadenitis, suppurated otitis) per year require a detailed investigation. Acute respiratory infections (ARI) are an important cause of morbidity and mortality in childhood. Low ARI is the main cause of pediatric consultations throughout the year. Pneumonia is still an important cause of infant mortality in many countries. When respiratory infections occur repeatedly, they force the doctor and the health team to identify the causes and factors involved in their recurrence. The high prevalence of recurrent obstructive bronchial symptoms should not mask other causes such as: malformations, foreign body, underlying diseases such as cystic fibrosis, neuromuscular diseases, heart diseases or immunological defects.

The evaluation of the child with recurrent infections should start with a history in which special attention to age, sex, perinatal history (prematurity, delay in cord fall), frequency, location, severity and complications of infections; presence or absence of a symptomfree interval; microbiology of any isolation and response or lack of response to antimicrobial therapy.In addition, underlying diseases and treatments with immunosuppression-inducing drugs, clinical manifestations of an autoimmune disease, history of atopy, surgical history (tonsillectomy, splenectomy, and abscesses), adverse drug, vaccines and transfusion reactions should be investigated. Among the family history is important to explore consanguinity of the parents, cases of early death, severe infections, atopy, autoimmune diseases, lymphoreticular neoplasms, drug addiction or risk factors for HIV / AIDS.

In the physical examination, weight and height should be assessed to identify a growth alteration or a recent weight loss. The presence of tonsils and lymph nodes, 
hepatosplenomegaly, skin lesions, dysmorphic facies and associated malformations (i.e. cardiac, skeletal) should be examined with special attention.

Children with recurrent infections can be included in four basic types of diagnostic categories:

\subsection{Probably Healthy Child}

The child is generally well between the episodes, the beginning of the infection is recent with no history of chronicity and often the environmental situation is new (admission to the nursery, more siblings), and the growth and development are normal. Half of the children who consult for recurrent infections correspond to this group and their study do not reveal an alteration of their immune response. The number of infections considered normal in a child under 2 years is very variable and according to some consensus, the average goes between 4 to 8 annual respiratory infections, reaching 12 episodes per year if they have older siblings, or attend day care centers or they are exposed to passive smoking. Most infections are viral; they can present up to 4 acute otitis media and 4 gastrointestinal infections per year.

\subsection{Allergic Child}

Growth and development are usually normal, disease episodes are not febrile and do not respond to antimicrobials. Their respiratory infection is usually accompanied by irritative cough, and family history of atopy and some stigma such as allergic wrinkle, mouth breathing, adenoid facies, and chronic cough are often present. Approximately $30 \%$ of patients with recurrent infections have an underlying allergic disease. Chronic rhinitis may be confused with recurrent upper respiratory infections. In a specialized center the main cause of recurrent pneumonia corresponds to children with wheezing / asthma syndrome.

\subsection{Child with Chronic or Immunosuppressed Disease}

In this group children have growth retardation, infections are continuous and the agent usually does not identify. In physical examination may appear abnormalities such as abdominal distension, rales, digital clubbing or dermatitis. The most frequent causes of secondary immunodeficiency are leukemia, lymphomas, other neoplasms, and treatments with immunosuppressant drugs, use of corticosteroids, transplantation, chronic renal failure, diabetes, Down syndrome, and HIV / AIDS infection. In children with recurrent pulmonary and sinus infections, especially if they are accompanied by malabsorption, anemia or nasal polyps, cystic fibrosis should be ruled out since its incidence and prevalence is greater than primary immunodeficiency (PID).

\subsection{Primary Immunodeficient Child}

Growth retardation is usually present, and lymph nodes or tonsils may be absent, infections of different types are in multiple sites, and unusual or opportunistic agents can be isolated and cultured, infections are serious and often have complications. Among the numerous PID syndromes there are 4 that are frequent, share clinical manifestations in terms of the prevalence of respiratory infections, are associated with allergic diseases, have alterations of immunoglobulins or antibodies and in many cases have a benign course, such as selective deficiency of $\operatorname{IgA}$, the transient hypogammaglobulinemia of childhood, the deficit of subclasses of $\operatorname{IgG}$ and the deficiency of specific antibodies. All require study and management by a specialist. In children with PID the greatest susceptibility to infections can be expressed as: increase in frequency, greater severity and / or duration of episodes, repeated infections without free interval, incomplete improvement between episodes, chronic evolution despite adequate treatment, dependence of antimicrobial treatment, severe or unexpected complication and infections caused by non-habitual or opportunistic agents.

When starting the study of children with recurrent infections it is convenient to rule out the anatomical causes in those patients with predominantly localized infections, and then the presence of a cause of secondary immunodeficiency should be considered.

To facilitate the suspicion and guide the appropriate detection of children with PID, different warning signs have been developed, and the best known is from the Jeffrey Modell Foundation (Table 1).

It is also useful to consider the acronym SPOR that corresponds to severe infections, Persistent infections, Opportunistic agents and Recurrent, especially if respiratory infections are associated with other extra pulmonary sites and there are 
phenotypic characteristics or family history of PID.

Table1. Warning signs for PID (Jeffrey Modell Foundation)

$>$ Four or more otic infections in 1 year

$>$ Two or more serious sinus infections in 1 year

$>$ Two or more months of antibiotics with little effect

$>$ Two or more pneumonias in 1 year

$>$ Failure to gain normally weight or grow in an infant

$>$ Recurrent deep abscesses of the skin or organs

$>$ Persistent oral candidiasis or cutaneous fungal infection

$>$ Need for intravenous antibiotics to control infections

$>$ Two or more invasive infections, including septicemia

Family history of PID

Once the study has been decided based on the history, and the physical examination and the warning signs, it is necessary to carry out general laboratory analysis: complete blood count, cultures and relevant microbiological examinations aimed at the etiological search of the infection, and radiological or complementary imaging studies.

In the evaluation of the innate and adaptive immune responses, it is necessary to carry out tests of all the possible components: antibodies, specific cellular immunity, phagocytic functions and complement system.

Depending on the infectious agent, some PID may be suspected as more probable, and after initial screening with a complete blood count, serum immunoglobulin levels (IgG, IgM, IgA and $\operatorname{IgE})$ and determination of total hemolytic Complement (CH50) to guide the most useful tests they should be requested. Currently, molecular biology and genetics assays for the definitive diagnosis of several PID are required (Table 2).

There is a group of clinical conditions that require a immediate study because they correspond to severe patients, with a high probability of having a serious immunodeficiency. Within these conditions are children with lymphopenia, with infections by opportunistic agents, with phenotypic features or symptoms that are associated with congenital immunodeficiencies or with a family history of an immunodeficiency with a known pattern of inheritance.
Table2. Relationship between frequent infections by agents and PID

\begin{tabular}{|c|c|c|}
\hline $\begin{array}{l}\text { INFECTIO } \\
\text { US AGENT }\end{array}$ & $\begin{array}{c}\text { LABORATO } \\
\text { RY STUDY }\end{array}$ & PID \\
\hline $\begin{array}{l}\text { S. } \\
\text { pneumoniae }\end{array}$ & $\begin{array}{l}\text { Specificantibod } \\
\text { ies }\end{array}$ & $\begin{array}{lr}\text { Specific } & \\
\text { antibodies } & \\
\text { deficiency } & \\
\text { IRAK4 } & \text { o } \\
\text { MYD88 defect }\end{array}$ \\
\hline $\begin{array}{l}\text { Viruses, } \\
\text { fungi, } \\
\text { parasites, } \\
\text { opportunists } \\
\text { agents }\end{array}$ & $\begin{array}{l}\text { Lymphocyte } \\
\text { Subtypes } \\
\text { Lymphoblastic } \\
\text { transformation } \\
\text { HIV }\end{array}$ & $\begin{array}{l}\text { Severe } \\
\text { combined } \\
\text { Immunodefici } \\
\text { ency (SCID) }\end{array}$ \\
\hline S. aureus & $\begin{array}{l}\text { Respiratoryburs } \\
\mathrm{t}(\text { Dihydroroda } \\
\text { mine test) } \\
\text { SerumIgE }\end{array}$ & $\begin{array}{l}\text { Chronic } \\
\text { granulomatous } \\
\text { disease } \\
\text { Hyper IgE } \\
\text { syndrome }\end{array}$ \\
\hline Candida & $\begin{array}{l}\text { Lymphocyte } \\
\text { Subtypes } \\
\text { Lymphoblastic } \\
\text { transformation } \\
\text { HIV }\end{array}$ & $\begin{array}{ll}\begin{array}{l}\text { STAT } \\
\text { defect }\end{array} & 1-3 \\
\text { IL12RB8, } & \\
\text { CARD 9 } & \end{array}$ \\
\hline $\begin{array}{l}\text { Mycobacteri } \\
\text { aSalmonella }\end{array}$ & $\begin{array}{l}\text { Molecularand } \\
\text { genetic study }\end{array}$ & $\begin{array}{l}\text { IL12- } \\
\text { Interferon } \gamma \\
\text { axis defect }\end{array}$ \\
\hline Neisseria & $\begin{array}{l}\text { C5-C9 } \\
\text { Complement } \\
\text { level }\end{array}$ & $\begin{array}{l}\text { Membrane } \\
\text { attack complex } \\
\text { defect }\end{array}$ \\
\hline
\end{tabular}

\section{REFERENCES}

[1] Quezada A. Primary Inmunodeficncy diseases: developing news. ARC Journal of Pediatrics 2016;2(1): 18-19

[2] Quezada A, Norambuena X, Bravo A, CastroRodriguez J. Recurrent pneumonia as warning manifestation for suspecting Primary Immunodeficiencies in children. J InvestigAllergolClinImmunol 2001;11(4):295299

[3] Stiehm ER. The four most common pediatricimmunodeficiencies. J Immunotoxicol 2008;5:227-234

[4] de Martino M, Ballotti S. The child with recurrent respiratory infections: normal or not? Pediatr Allergy Immunol 2007:18(Suppl. 18):13-18

[5] Slatter MA, Gennery AR. Clinical Immunology Review Series: An approach to the patient with recurrent infections in childhood. ClinExpImmunol 2008;152:389-396

[6] Aghamohammadia A, Moina M, Karimib A. Immunologic evaluation of patients with recurrent ear, nose, and throat infections. Am J Otolaryngol Head Neck Med Surg 2008;29:385392

[7] Quezada A, Norambuena X, Inostroza J, Rodríguez J. Specific antibody deficiency with normal immunoglobulin concentration in children with recurrent respiratory infections. AllergolImmunopathol (Madr). 2015;43(3):292- 
297.

[8] Wall LA, Dimitriades VR, MD, Sorensen RU. Specific Antibody Deficiencies. Immunol Allergy Clin N Am 2015; 35(4):659-70.
[9] Hernandez-Trujillo VP. Approach to Children with Recurrent Infections ImmunolAllergClin N Amer 2015;35(4):625-36

Citation: Arnoldo Quezada. The Child with Recurrent Infections. ARC Journal of Pediatrics.2018; 4(2): 17-20. doi:dx.doi.org/10.20431/2455-5711.0402004.

Copyright:@ 2018 Authors. This is an open-access article distributed under the terms of the Creative Commons Attribution License, which permits unrestricted use, distribution, and reproduction in any medium, provided the original author and source are credited. 